\title{
PENGOLAHAN LIMBAH POLIPROPILEN MENJADI BAHAN BAKAR CAIR MELALUI METODE PIROLISIS
}

\author{
Restina Bemis, Novesar Jamarun, dan Syukri Arief \\ Laboratorium Material Universitas Andalas \\ E-mail : novesar62@yahoo.com
}

\begin{abstract}
Plastics become the biggest environmental problem when it accumulate in landfills because its nonbiodegradable properties. To handle the problems, the plastics were processed to produce liquid fuels by means pyrolysis method which was in this case with and without a catalyst. In this work, polypropylene was used as a precursor and $\mathrm{SiO}_{2}$, zeolites, $\mathrm{CaO}, \mathrm{Fe}$ as catalysts. FTIR spectrum of pyrolized polypropylene with and without catalysts both have shown $\mathrm{C}=\mathrm{C}$ functional group at $1648 \mathrm{~cm}^{-1}$. GCMS analysis confirmed the availability of chain length of hydrocarbon between $\mathrm{C}_{7}$ $\mathrm{C}_{27}$ which is mixture of kerosene and diesel fractions. Catalysts can lower the temperature and time reaction of pyrolysis process as they increase rendement $(\%)$ of product. Liquid fuels that produced from polypropylene pyrolysis without catalyst was $72.06 \%$, and with catalysts were $79.59 \%\left(\mathrm{SiO}_{2}\right)$, $74.76 \%$, (zeolite), $76.80 \%(\mathrm{CaO})$, and $76.83 \%(\mathrm{Fe})$.
\end{abstract}

Keywords : Pyrolysis, polypropylene, catalyst

\section{PENDAHULUAN}

Komponen yang sangat erat dalam kehidupan makhluk hidup ialah udara, tanah, dan air. Namun, jika udara, tanah, dan air tersebut telah tercemar maka dapat menyebabkan penurunan terhadap kualitas kehidupan. Penyebab tercemarnya udara, tanah, dan air tersebut adalah pencemaran lingkungan karena aktivitas manusia yang tidak dapat terlepas dari penggunaan plastik setiap harinya.

Faktor-faktor yang mendorong penggunaan plastik antara lain ringan, tidak mudah pecah, efisiensi energi, desain yang menarik, dan ketersediaan produk dengan kisaran harga yang bervariasi serta mudah didapatkan. Hal inilah yang menyebabkan penggunaan plastik meningkat dan tidak terkontrol setiap harinya $^{[1]}$.

Menurut data statistik persampahan domestik Indonesia tahun 2008, jenis sampah plastik menduduki peringkat ke-2, sebesar 5,4 juta ton/tahun (14\%). (Sumber: Kementerian Lingkungan Hidup, 2008). Plastik yang telah digunakan akan menjadi limbah dan menumpuk pada landfill karena sifatnya yang non-biodegradable dan butuh waktu yang lama untuk dapat diuraikan secara alamiah di tanah.

Penumpukan sampah yang terlalu lama akan menimbulkan bau yang tidak enak yang dapat menyebabkan kualitas udara pada lingkungan menjadi menurun. Sementara, jika dilakukan pembakaran limbah plastik ini dapat menghasilkan gas berbahaya seperti karbon dioksida $\left(\mathrm{CO}_{2}\right)$, sulfur oksida $\left(\mathrm{SO}_{\mathrm{x}}\right)$, dan nitrogen oksida $\left(\mathrm{NO}_{\mathrm{x}}\right)$ ke udara ${ }^{[2]}$.

Salah satu alternatif untuk mengatasi permasalahan ini adalah dengan memanfaatkan potensi yang ada pada plastik menjadi bahan bakar. Beberapa jenis plastik yang dapat dimanfaatkan menjadi bahan bakar seperti High Density Polyethylene (HDPE), Low Density Polyethylene (LDPE), polipropilen, polistiren, polivinilklorida, dan lain-lainnya.

Limbah plastik tersebut dapat diolah menjadi bahan bakar minyak dengan menggunakan beberapa metode, seperti pyrolysis, thermal cracking, catalytic cracking, catalytic degradation, dan hydrocracking ${ }^{[1-6]}$. Diantara metode pengolahan plastik menjadi bahan bakar tersebut, pirolisis merupakan salah satu yang paling menjanjikan karena limbah plastik 
dapat diolah menjadi bahan bakar yang berharga.

Pirolisis dapat dilakukan dengan atau tanpa katalis. Keuntungan metode ini dengan menggunakan katalis adalah dapat menurunkan temperatur reaksi. Hal inilah yang menyebabkan kenapa proses yang menggunakan katalis lebih banyak dilakukan untuk meningkatkan kualitas produk ${ }^{[3]}$.

Beberapa jenis katalis padat yang telah digunakan para peneliti untuk degradasi plastik menjadi bahan bakar, seperti silika-alumina, aluminium oksida $\left(\mathrm{Al}_{2} \mathrm{O}_{3}\right)$, zink oksida $\left(\mathrm{ZnO}_{2}\right)$, silika oksida $\left(\mathrm{SiO}_{2}\right)$, arsenik oksida $\left(\mathrm{As}_{2} \mathrm{O}_{3}\right)$, kromium oksida $\left(\mathrm{Cr}_{2} \mathrm{O}_{3}\right)$, besi oksida $\left(\mathrm{Fe}_{2} \mathrm{O}_{3}\right)$, timbal oksida $\left(\mathrm{PbO}_{2}\right)$, vanadium oksida $\left(\mathrm{V}_{2} \mathrm{O}_{5}\right)$, timbal tetra asetat $\left(\mathrm{Pb}(\mathrm{OAC})_{4}\right)$, katalis FCC (Fluid Catalytic Cracking) MCM-41, sulfat yang dimodifikasi oleh zirkonium, dan zeolit $^{[1,3-5,7]}$.

Latar belakang inilah yang mendasari dilakukannya penelitian dengan memanfaatkan potensi dari limbah plastik jenis polipropilen menjadi bahan bakar cair menggunakan metode pirolisis dengan dan tanpa adanya katalis. Katalis yang digunakan dalam penelitian ini adalah $\mathrm{SiO}_{2}$, zeolit, $\mathrm{CaO}$, dan $\mathrm{Fe}$. Dari keempat jenis katalis ini, dapat diketahui katalis mana yang efektif dalam proses pengolahan plastik menjadi bahan bakar. Beberapa faktor yang diperhatikan dalam penelitian ini, seperti pengaruh jenis katalis, temperatur reaksi, persen (\%) produk, dan waktu lamanya proses yang digunakan dalam mengubah plastik menjadi bahan bakar cair.

\section{METODOLOGI PENELITIAN}

\section{Alat dan Bahan}

Alat yang digunakan antara lain pemanas bunsen, labu distilasi $300 \mathrm{~mL}$, kondensor, termometer $400{ }^{\circ} \mathrm{C}$, erlenmeyer $250 \mathrm{~mL}$, dan piknometer. Instrumen yang digunakan adalah Fourier Transform Infra Red (FTIR) JASCO FT/IR 460 plus dan GCMS-QP2010 Plus.

Bahan yang digunakan adalah limbah gelas plastik air mineral (polipropilen), katalis $\mathrm{SiO}_{2}$, zeolit, $\mathrm{CaO}$, dan $\mathrm{Fe}$.

\section{Prosedur Kerja}

\section{Perlakuan pada katalis}

Sumber zeolit dan $\mathrm{CaCO}_{3}$ diambil di kawasan Sumatera Barat sedangkan $\mathrm{SiO}_{2}$ dan $\mathrm{Fe}$ merupakan katalis sintetis. Perlakuan aktivasi dilakukan pada katalis zeolit dan $\mathrm{CaO}$. Sebanyak $10 \mathrm{~g}$ zeolit dipanaskan dengan menggunakan furnace pada temperatur $400{ }^{\circ} \mathrm{C}$ selama 4 jam. Katalis $\mathrm{CaO}$ diperoleh dengan memanaskan $10 \mathrm{~g} \mathrm{CaCO}_{3}$ pada temperatur 800 ${ }^{\circ} \mathrm{C}$ selama 1 jam.

\section{Proses pengolahan polipropilen menjadi bahan bakar cair}

Sebanyak $150 \mathrm{~g}$ polipropilen dikumpulkan, disortir, dan dibersihkan dari kontaminasinya. Selanjutnya plastik tersebut dipotong menjadi bagian yang lebih kecil.

\section{Pirolisis tanpa katalis}

Sebanyak $30 \mathrm{~g}$ polipropilen dimasukkan ke dalam labu distilasi dan dipanaskan dengan menggunakan bunsen hingga meleleh kemudian didiamkan semalam. Selanjutnya plastik hasil lelehan didestilasi dengan menggunakan peralatan destilasi dan pemanas bunsen. Uap hasil distilasi didinginkan melalui kondensor ditampung dengan erlenmeyer. Volume hasil akhir yang diperoleh kemudian diukur untuk mengetahui persentase produk yang didapatkan.

\section{Pirolisis dengan katalis}

Sebanyak 30 g polipropilen dan 3 gram katalis, masing-masingnya $\left(\mathrm{SiO}_{2}\right.$, zeolit, $\mathrm{CaO}$, dan $\left.\mathrm{Fe}\right)$ dimasukkan ke dalam labu distilasi dan dilakukan proses pirolisis seperti pada pirolisis polipropilen tanpa menggunakan katalis.

\section{HASIL DAN PEMBAHASAN}

Proses pengolahan polipropilen menjadi bahan bakar cair dilakukan dengan dan tanpa menggunakan katalis. Katalis yang digunakan dalam penelitian ini yakni silika oksida $\left(\mathrm{SiO}_{2}\right)$, zeolit, kalsium oksida $(\mathrm{CaO})$, dan serbuk besi 
(Fe). Dari keempat katalis ini dapat dilihat pengaruh yang diberikan oleh katalis tersebut terhadap temperatur reaksi, waktu reaksi, dan persen produk yang dihasilkan dalam proses pengolahan polipropilen menjadi bahan bakar cair. Hasil analisis pengaruh katalis ditunjukkan pada Tabel 1.

Dari hasil pengamatan umum menunjukkan bahwa pirolisis dengan menggunakan katalis $\mathrm{SiO}_{2}$ merupakan proses yang menghasilkan produk lebih baik jika dibandingkan dengan katalis yang lainnya, dilihat dari pengaruh temperatur reaksi, total waktu reaksi, dan persen produk yang dihasilkan. Hal ini diindikasikan karena $\mathrm{SiO}_{2}$ memiliki pori yang berukuran mesopori. Peningkatan luas permukaan dan volume pori katalis juga mendukung peningkatan aktivitas katalis. Hal ini disebabkan karena lebih besarnya kemungkinan reaktan untuk masuk ke dalam pori katalis. Semakin besarnya peluang reaktan untuk masuk ke dalam pori berarti semakin besar pula peluang terjadinya reaksi katalitik antara reaktan dengan permukaan katalis ${ }^{[8-9]}$.

Pengaruh katalis terhadap temperatur reaksi, waktu reaksi, dan persen produk dalam pirolisis polipropilen

Dari gambar 1 dapat dilihat pengaruh yang diberikan oleh katalis terhadap temperatur reaksi, waktu reaksi, dan persentase (\%) produk yang dihasilkan.

Reaksi dengan menggunakan katalis $\mathrm{SiO}_{2}$ memiliki temperatur reaksi yang lebih rendah jika dibandingkan dengan katalis yang lainnya dan reaksi tanpa katalis, yakni $130{ }^{\circ} \mathrm{C}$. Namun, disini terlihat adanya penyimpangan pada penggunaan katalis $\mathrm{Fe}$ yang ternyata memiliki temperatur reaksi yang lebih tinggi jika dibandingkan dengan reaksi tanpa katalis. Katalis Fe memiliki temperatur reaksi $166{ }^{\circ} \mathrm{C}$ sedangkan reaksi tanpa katalis memiliki temperatur reaksi $150{ }^{\circ} \mathrm{C}$. Hal ini menunjukkan bahwa katalis $\mathrm{Fe}$ kurang efisien dalam menurunkan temperatur reaksi dalam proses pirolisis polipropilen.

Waktu rata-rata dari pirolisis $30 \mathrm{~g}$ polipropilen adalah $1-2$ jam untuk reaksi yang menggunakan katalis. Sedangkan untuk reaksi tanpa katalis memerlukan waktu reaksi selama 4 jam untuk mampu mendegradasi polipropilen menjadi bahan bakar cair.

Katalis $\mathrm{SiO}_{2}$ memiliki waktu reaksi yang lebih cepat jika dibandingan dengan katalis lainnya dan reaksi tanpa katalis, yakni 100 menit untuk dapat mendegradasi polipropilen menjadi bahan bakar cair. Sementara itu, katalis $\mathrm{CaO}$ memiliki waktu reaksi 105 menit, katalis $\mathrm{Fe}$ memiliki waktu reaksi 110 menit, dan katalis zeolit memiliki waktu reaksi 113 menit.

Tabel 1. Pengamatan umum untuk semua proses pirolisis

\begin{tabular}{lccccc}
\hline \multirow{2}{*}{ Parameter } & \multicolumn{5}{c}{ Katalis yang digunakan } \\
\cline { 2 - 6 } & $\begin{array}{c}\text { Tanpa } \\
\text { Katalis }\end{array}$ & $\mathbf{S i O}_{2}$ & Zeolit & $\mathbf{C a O}$ & $\mathbf{F e}$ \\
\hline Temperatur tetesan pertama $\left({ }^{\circ} \mathrm{C}\right)$ & 150 & 130 & 133 & 135 & 166 \\
Temperatur tetesan terakhir $\left({ }^{\circ} \mathrm{C}\right)$ & 160 & 160 & 195 & 180 & 166 \\
Total waktu reaksi (menit) & 240 & 100 & 113 & 105 & 110 \\
Volume produk cair yang diperoleh $(\mathrm{mL})$ & 30 & 33 & 31 & 32 & 32 \\
Massa Jenis produk $(\mathrm{g} / \mathrm{mL})$ & 0,7206 & 0,7236 & 0,7235 & 0,72 & 0,7203 \\
Persentase produk $(\%)$ & 72,06 & 79,59 & 74,76 & 76,80 & 76,83 \\
\hline
\end{tabular}




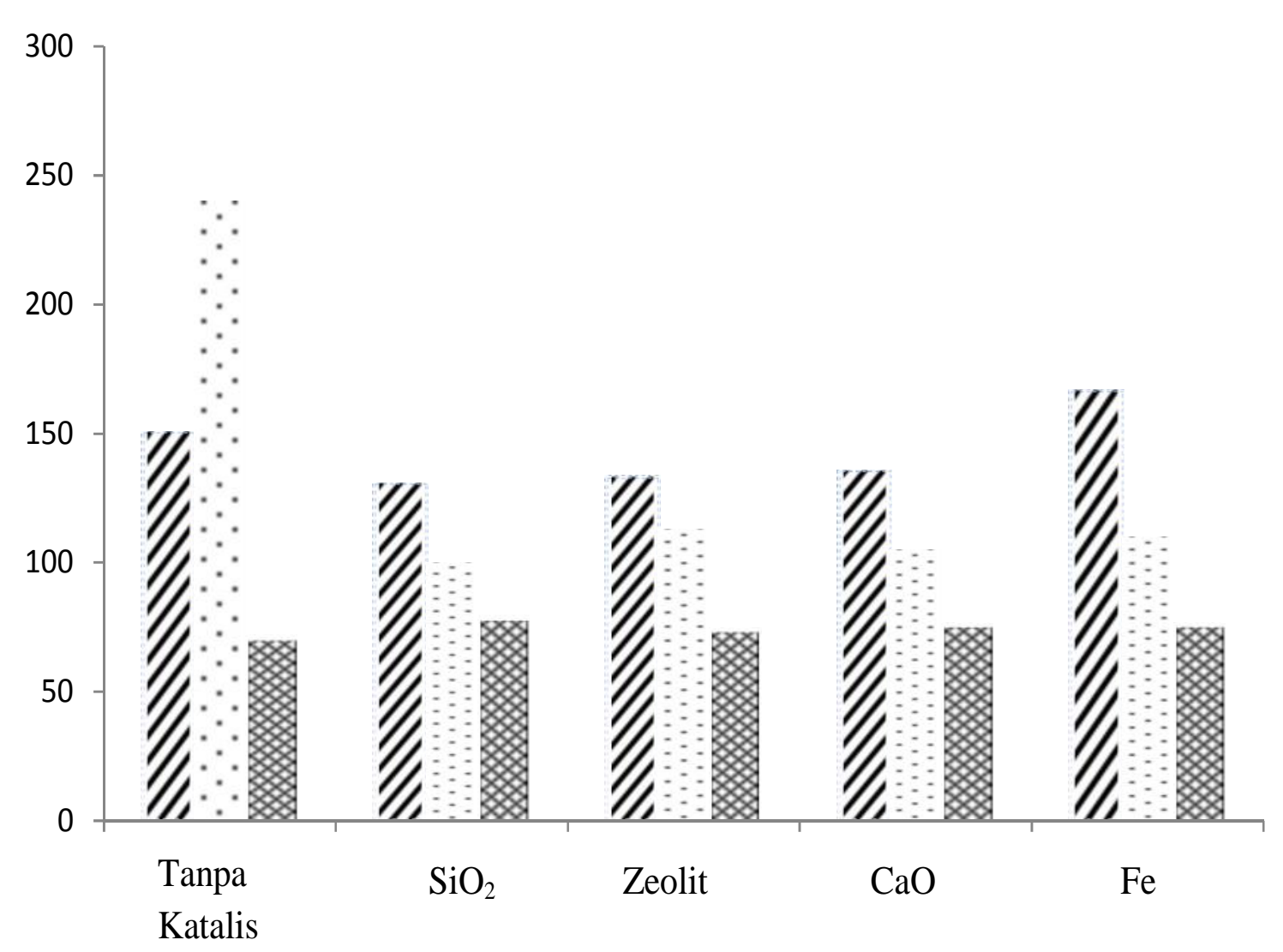

Keterangan :

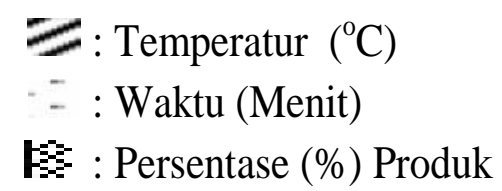

Gambar 1. Pengaruh yang diberikan oleh katalis terhadap temperatur reaksi, waktu reaksi, dan persentase $(\%)$ produk yang dihasilkan

Pirolisis dengan menggunakan katalis $\mathrm{SiO}_{2}$ diperoleh produk dengan persentase terbesar yakni $79,596 \%$, selanjutnya $76,832 \%$ untuk pirolisis polipropilen dengan menggunakan katalis $\mathrm{Fe}, \quad 76,80 \%$ dengan menggunakan katalis $\mathrm{CaO}$, dan $74,762 \%$ dengan menggunakan katalis zeolit. Sementara, untuk pirolisis polipropilen tanpa menggunakan katalis hanya menghasilkan sekitar $72,06 \%$ produk cair. Produk yang dihasilkan dari metode pemecahan rantai polimer seperti proses pirolisis ini umumnya menghasilkan sekitar $70-80 \%$ cairan dan $5-10 \%$ gas ${ }^{[10]}$. Sehingga dapat dilihat bahwa pirolisis dengan menggunakan katalis mampu menurunkan temperatur dan waktu reaksi serta menghasilkan produk cair dengan persentase produk yang lebih besar jika dibandingkan dengan pirolisis tanpa menggunakan katalis ${ }^{[11]}$. 
Tabel 2. Hasil analisis FTIR pirolisis polipropilen dengan dan tanpa menggunakan katalis

\begin{tabular}{|c|c|c|c|c|c|c|c|c|c|}
\hline \multirow[b]{2}{*}{ Katalis } & \multicolumn{9}{|c|}{ Angka gelombang } \\
\hline & $\begin{array}{c}=\mathrm{C}-\mathrm{H} \\
\text { stretching }\end{array}$ & $\begin{array}{c}\mathrm{C}-\mathrm{H} \\
\text { stretching } \\
\text { dari } \mathrm{CH}_{3}\end{array}$ & $\begin{array}{c}\mathrm{C}-\mathrm{H} \\
\text { stretching } \\
\text { dari } \mathrm{CH}_{2}\end{array}$ & $\begin{array}{c}\text { non- } \\
\text { konjugasi }\end{array}$ & $\begin{array}{c}\mathrm{C}=\mathrm{C} \\
\text { stretching }\end{array}$ & $\begin{array}{c}\mathrm{CH2} \\
\text { scissoring }\end{array}$ & $\begin{array}{c}\mathrm{C}-\mathrm{H} \\
\text { bending } \\
\text { dari } \mathrm{CH}_{2}\end{array}$ & $\begin{array}{c}-\mathrm{HC}=\mathrm{CH}- \\
\text { (trans) }\end{array}$ & $\begin{array}{c}=\mathrm{C}-\mathrm{H} \\
\text { bending }\end{array}$ \\
\hline $\begin{array}{l}\text { Tanpa } \\
\text { katalis }\end{array}$ & 3073,98 & & 2919,7 & $\begin{array}{l}1779,97 \\
1706,69\end{array}$ & 1650,77 & 1456,96 & 1378,85 & $\begin{array}{r}1156,12 \\
968,09\end{array}$ & 888,059 \\
\hline $\mathrm{SiO} 2$ & 3073,98 & 2954,41 & 2918,73 & & 1648,84 & 1455,99 & 1375,96 & $\begin{array}{l}1156,12 \\
969,055\end{array}$ & 887,095 \\
\hline Zeolit & 3073,98 & 2955,98 & 2920,66 & & 1648,84 & 1455,99 & 1376,93 & $\begin{array}{l}1157,08 \\
970,091\end{array}$ & 888,059 \\
\hline $\mathrm{CaO}$ & 3074,94 & 2957,3 & 2919,7 & & 1646,91 & 1456,86 & 1375 & $\begin{array}{l}1156,12 \\
969,055\end{array}$ & 888,059 \\
\hline $\mathrm{Fe}$ & 3073,98 & & 2918,73 & $\begin{array}{l}1779,97 \\
1710,55\end{array}$ & 1646,91 & 1456,96 & 1379,82 & $\begin{array}{r}1155,15 \\
968,09\end{array}$ & 889,987 \\
\hline
\end{tabular}

\section{Hasil analisis spektrofotometer FT-IR}

Hasil analisis FTIR dari pirolisis polipropilen dengan dan tanpa katalis ditunjukkan pada Tabel 2. Dari hasil FT-IR didapatkan gugus fungsi $=\mathrm{C}-\mathrm{H}$ stretching, dimana pada senyawa alkena gugus $=\mathrm{C}-\mathrm{H}$ stretching terletak antara $3100-3000 \mathrm{~cm}^{-1}$. Gugus fungsi ini didukung oleh munculnya gugus fungsi $\mathrm{C}=\mathrm{C}$ stretching yang terletak antara $1680-1600 \mathrm{~cm}^{-1}$. Selanjutnya adanya gugus fungsi $\mathrm{C}-\mathrm{H}$ stretching dari $\mathrm{CH}_{3}, \mathrm{C}-\mathrm{H}$ stretching dari $\mathrm{CH}_{2}$, dan gugus fungsi non-konjugasi dari senyawa hidrokarbon. Selain itu, didapatkan pula gugus $\mathrm{CH}_{2}$ scissoring, $\mathrm{C}-\mathrm{H}$ bending dari $\mathrm{CH}_{3}$ dan fungsi dari $-\mathrm{HC}=\mathrm{CH}-$ (trans). Gugus fungsi dari $=\mathrm{C}-\mathrm{H}$ bending dari alkena terletak antara $1000-600 \mathrm{~cm}^{-1[12-13]}$.

\section{Hasil Analisis GC-MS}

\section{Tanpa menggunakan katalis}

Hasil GCMS pada Gambar 2 menunjukkan bahwa total waktu retensi dari senyawa senyawa hasil pirolisis polipropilen tanpa katalis ini adalah 3-8 menit seperti pada Tabel 3. Senyawa yang diperoleh dari hasil pirolisis polipropilen ini memiliki rantai hidrokarbon antara $\mathrm{C}_{9}-\mathrm{C}_{27}$ (Tabel 3) yang diindikasikan bahwa senyawa ini merupakan senyawa campuran dari fraksi kerosene dan diesel. Fraksi kerosene memiliki panjang rantai karbon $\mathrm{C}_{8}-\mathrm{C}_{19}$ sedangkan panjang rantai karbon untuk diesel adalah $\mathrm{C}_{7}-\mathrm{C}_{27}{ }^{[14]}$

\section{Dengan menggunakan Katalis}

Hasil analisis GCMS dari pirolisis polipropilen dengan menggunakan katalis hampir sama dengan proses pirolisis polipropilen tanpa menggunakan katalis. Total waktu retensi dari senyawa - senyawa hasil pirolisis polipropilen dengan menggunakan katalis $\mathrm{SiO}_{2}$, zeolit dan Fe adalah 3-9 menit dengan rantai hidrokarbon antara $\mathrm{C}_{7}-\mathrm{C}_{28}$. Sedangkan dengan menggunakan katalis $\mathrm{CaO}$ adalah 5-23 menit dengan rantai karbon antara $\mathrm{C}_{11}-\mathrm{C}_{54}$. Senyawasenyawa ini diindikasikan merupakan campuran dari fraksi kerosen dan diesel. Fraksi kerosen memiliki panjang rantai karbon $\mathrm{C}_{8}-\mathrm{C}_{19}$ sedangkan panjang rantai karbon untuk diesel adalah $\mathrm{C}_{7}-\mathrm{C}_{27}$. ${ }^{[14]}$

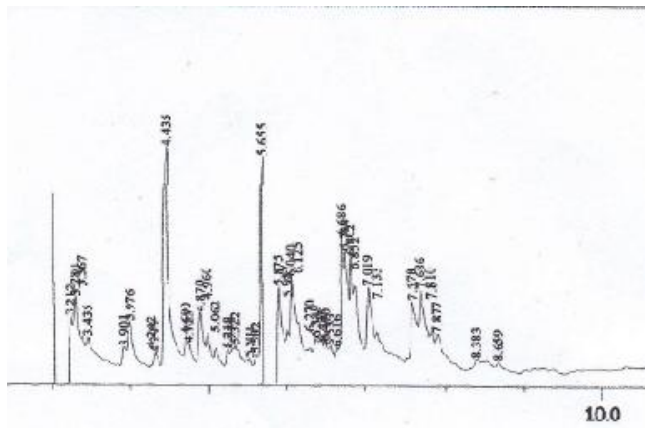

Gambar 2. Kromatogram GCMS pirolisis polipropilen tanpa menggunakan katalis 

Tabel 3 : Data GCMS dari pirolisis polipropilen tanpa menggunakan katalis.

\begin{tabular}{|c|c|c|c|}
\hline $\begin{array}{l}\text { Waktu Retensi } \\
\text { (Menit) }\end{array}$ & Nama Senyawa & $\begin{array}{c}\text { Rumus } \\
\text { Senyawa }\end{array}$ & $\begin{array}{c}\text { Berat } \\
\text { Molekul }\end{array}$ \\
\hline 3,212 & metil-heptanoat & $\mathrm{C}_{9} \mathrm{H}_{18} \mathrm{O}_{2}$ & 158 \\
\hline 3,28 & $3[($ asetiloksi)metil]-3,4-dimetil-2-pentanon & $\mathrm{C}_{9} \mathrm{H}_{15} \mathrm{O}_{3}$ & 171 \\
\hline 3,367 & 2,4-dimetil-2,6 oktadiene & $\mathrm{C}_{10} \mathrm{H}_{18}$ & 138 \\
\hline 3,435 & 2,5-dimetil-1,6 oktadiene & $\mathrm{C}_{10} \mathrm{H}_{18}$ & 138 \\
\hline 3,435 & 7-metil-1-undekena & $\mathrm{C}_{12} \mathrm{H}_{24}$ & 168 \\
\hline 3,976 & 2,6-dimetil-nonana & $\mathrm{C}_{11} \mathrm{H}_{24}$ & 156 \\
\hline 4,295 & 2,2-dimetil,3-decena & $\mathrm{C}_{12} \mathrm{H}_{24}$ & 168 \\
\hline 4,435 & 2,6,8-trimetil-4-nonena & $\mathrm{C}_{12} \mathrm{H}_{24}$ & 168 \\
\hline 4,69 & 2-metil-2-undekanatiol & $\mathrm{C}_{12} \mathrm{H}_{26} \mathrm{~S}$ & 202 \\
\hline 4,725 & 4,6,8-trimetil-1-nonena & $\mathrm{C}_{12} \mathrm{H}_{24}$ & 168 \\
\hline 4,87 & $\begin{array}{l}\text { 1-hidroksiisopropil-2,3-dimetil- } \\
\text { siklopentana }\end{array}$ & $\mathrm{C}_{10} \mathrm{H}_{20} \mathrm{O}$ & 156 \\
\hline 4,96 & 2,4-dietil-1-metilsikloheksana & $\mathrm{C}_{11} \mathrm{H}_{22}$ & 154 \\
\hline 5,062 & 2,4-dietil-1-metilsikloheksana & $\mathrm{C}_{11} \mathrm{H}_{22}$ & 154 \\
\hline 5,218 & 2,4-dietil-1-metilsikloheksana & $\mathrm{C}_{11} \mathrm{H}_{22}$ & 154 \\
\hline 5,275 & 4,6-dimetil-dodekana & $\mathrm{C}_{14} \mathrm{H}_{30}$ & 198 \\
\hline 5,322 & 2,6,11-trimetil-dodekana & $\mathrm{C}_{15} \mathrm{H}_{32}$ & 212 \\
\hline 5,501 & 2,3,3-trimetil-1,7-oktadiena & $\mathrm{C}_{11} \mathrm{H}_{22}$ & 152 \\
\hline 5,582 & 2,6,6-trimetil-bisiklo[3.1.1]-heptan-3-on & $\mathrm{C}_{10} \mathrm{H}_{16} \mathrm{O}$ & 152 \\
\hline 5,655 & 1-tridekanol & $\mathrm{C}_{13} \mathrm{H}_{28} \mathrm{O}$ & 200 \\
\hline 5,875 & 7-metil-1-undekena & $\mathrm{C}_{12} \mathrm{H}_{24}$ & 168 \\
\hline 5,987 & 1-heksakosanol & $\mathrm{C}_{26} \mathrm{H}_{54} \mathrm{O}$ & 382 \\
\hline 6,04 & 1,19-elkosadiena & $\mathrm{C}_{20} \mathrm{H}_{38}$ & 278 \\
\hline 6,125 & 2,6,6-trimetil-bisiklo[3.1.1]-heptan-3-on & $\mathrm{C}_{10} \mathrm{H}_{16} \mathrm{O}$ & 152 \\
\hline 6,27 & 3,7,11-trimetil-1-dodekanol & $\mathrm{C}_{15} \mathrm{H}_{32} \mathrm{O}$ & 228 \\
\hline 6,349 & tetrapropilen & $\mathrm{C}_{12} \mathrm{H}_{24}$ & 168 \\
\hline 6,425 & 2,3,5,8-tetrametil-dekana & $\mathrm{C}_{14} \mathrm{H}_{30}$ & 198 \\
\hline 6,47 & 2,3,5,8-tetrametil-dekana & $\mathrm{C}_{14} \mathrm{H}_{30}$ & 198 \\
\hline 6,533 & eikosil-sikloheksana & $\mathrm{C}_{26} \mathrm{H}_{54}$ & 366 \\
\hline 6,616 & 7,11-dimetil-10-dodeken-1-ol & $\mathrm{C}_{14} \mathrm{H}_{28} \mathrm{O}$ & 212 \\
\hline 6,686 & 1-tridekanol & $\mathrm{C}_{13} \mathrm{H}_{8} \mathrm{O}$ & 200 \\
\hline 6,724 & 1-tridekanol & $\mathrm{C}_{13} \mathrm{H}_{28} \mathrm{O}$ & 200 \\
\hline 6,802 & 1-tridekanol & $\mathrm{C}_{13} \mathrm{H}_{28} \mathrm{O}$ & 200 \\
\hline 6,852 & 1-nonadekena & $\mathrm{C}_{19} \mathrm{H}_{38}$ & 266 \\
\hline 7,019 & $\begin{array}{l}\text { 1-hidroksiisopropil-2,3-dimetil- } \\
\text { siklopentana }\end{array}$ & $\mathrm{C}_{10} \mathrm{H}_{20} \mathrm{O}$ & 156 \\
\hline 7,133 & 2,6,6-trimetil-bisiklo[3.1.1]-heptan-3-on & $\mathrm{C}_{10} \mathrm{H}_{16} \mathrm{O}$ & 152 \\
\hline 7,578 & 1-heptakosanol & $\mathrm{C}_{27} \mathrm{H}_{56} \mathrm{O}$ & 396 \\
\hline 7,686 & 1-nonadekena & $\mathrm{C}_{19} \mathrm{H}_{38}$ & 266 \\
\hline 7,81 & 1-heptakosanol & $\mathrm{C}_{27} \mathrm{H}_{56} \mathrm{O}$ & 396 \\
\hline 7,877 & $\begin{array}{l}\text { 1-hidroksiisopropil-2,3-dimetil- } \\
\text { siklopentana }\end{array}$ & $\mathrm{C}_{10} \mathrm{H}_{20} \mathrm{O}$ & 156 \\
\hline 8,383 & 1-heptakosanol & $\mathrm{C}_{27} \mathrm{H}_{56} \mathrm{O}$ & 396 \\
\hline 8,659 & Germakrana-B & $\mathrm{C}_{15} \mathrm{H}_{30}$ & 210 \\
\hline
\end{tabular}




\section{KESIMPULAN}

Pirolisis polipropilen dengan dan tanpa katalis telah dilakukan untuk mengolah polipropilen menjadi bahan bakar cair. Hasil analisis FTIR menunjukkan adanya gugus fungsional $\mathrm{C}=\mathrm{C}$ dari senyawa hidrokarbon dan hasil analisis GCMS menunjukkan panjang rantai karbon antara $\mathrm{C}_{7}-\mathrm{C}_{27}$ yang merupakan campuran dari fraksi kerosene dan diesel. Katalis mampu menurunkan temperatur dan mempercepat waktu reaksi pirolisis polipropilen serta meningkankan persentase (\%) produk. Bahan bakar cair yang diperoleh dari pirolisis polipropilen tanpa katalis sebanyak 72,06\%, dengan menggunakan katalis $\mathrm{SiO}_{2}$ sebanyak $79,59 \%$, dengan menggunakan katalis zeolit sebanyak 74,76\%, dengan menggunakan katalis $\mathrm{CaO}$ sebanyak $76,80 \%$, dan dengan menggunakan katalis Fe sebanyak 76,83\%.

\section{DAFTAR PUSTAKA}

1. Osueke and C. O. Engr, Conversion of waste plastic (polyethylene) to fuel by means of pyrolysis, Internationa Journal of Advanced Engineering Science and Technologies., 4, 021-024, (2011).

2. Sarker, Moinuddin, M. M. Rashid, and M. Molla, Waste plastic conversion into chemical product like napthan, Journal of fundamentals of renewable energy and applications., 1, (2011).

3. Salman, Muhammad, R. Rehman, U. Shafique, T. Mahmud, B. Ali, Comparative thermal and catalytic recycling of low density polyethylene into diesel-like oil using different commercial catalysts. Journal Electronic Journal of Environmental, Agricultural and Food Chemistry., 11(2), 96-105, (2012).

4. Y. H. Lin and M. H. Yang, Catalytic reaction of post-consumer polymer waste over fluidised cracking catalysts for producing hydrocarbons, Journal of Molecular Catalyst A : Chemical., 113122, (2005).

5. M. N. Almustapha, J. M. Andresen, Catalytic conversion of high density polyethylene (HDPE) polymer as a means of recovering valuable energy content from the plastic wastes, International
Conference on Petroleum and Sustainable Development IPCBEE., 26, (2011).

6. D. Weibing, J. Liang, and L. L. Anderson, Hydrocracking of waste plastics to clean liquid fuels, Department of Chemical and Fuels Engineering.

7. D. C. Tiwari, E. Ahmad, and K. Singh Catalytic degradation of waste plastic into fuel range hydrocarbons, International Journal of Chemical Research., 1(2), 3136, (2009).

8. R. G. Rodríguez, J. A. Montoya, J. A. De Los Reyes, and T. Viveros, Mesoporous silica gels and $\mathrm{TiO}_{2} / \mathrm{SiO}_{2}$ and $\mathrm{ZrO}_{2}-\mathrm{SiO}_{2}$ mixed oxides prepared via the sol-gel Method, (2006).

9. Windarti, Tri, dan A. Suseno, Preparasi katalis zeolit alam asam sebagai katalis dalam proses pirolisis katalitik polietilena, Fakultas MIPA Universitas Diponegoro., 7(3), (2004).

10. Y. Sakata, M. A. Uddin, Koizumi, and Murata, Catalytic degradation of polypropylene into liquid hydrocarbon using silica-alumina catalyst, Journal Analytical Application Pyrolysis., 245246, (1996).

11. S. Toju and K. Daibo, Plastic Catalytic Degradation Study of The Role of External Catalytic Surface, Catalytic Reusability And Temperature Effects, A Thesis : Department of Chemical Engineering, University College London, London, WC1E 7JE, (2009).

12. B. Stuart, Infrared Spectroscopy : Fundamentals and Apllications. Analytical Techniques In The Sciences, (2004).

13. Sarker, Moinuddin et al, Waste Plastic Conversion into Hydrocarbon Fuel Materials, Department of Research and Development.

14. Sarker, Moinuddin, M. M. Rashid, dan M. S. Rahman, Conventional Fuel Generated From Polypropylene (PP) Waste Plastic Kerosen / Jet / Aviation Grade With Activated Carbon, International Journal of Modern Engineering Research., 2(4), 2168-2173, (2012). 